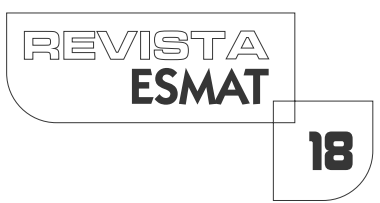

\title{
EXTRATERRITORIALIDADE, AMBIENTE E PESCA INN NO DIREITO DA UNIÃO EUROPEIA
}

EXTRATERRITORIALITY, ENVIRONMENT AND

INN FISHING IN EUROPEAN UNION LAW

Rute Saraiva

Doutora em Ciências Jurídico-Económicas. Universidade de Lisboa, Faculdade de Direito.

\section{RESUMO}

A União Europeia recorre amiúde, no plano de problemas transnacionais do foro ambiental, a mecanismos unilaterais que estendem o seu poder regulatório para lá do espaço comunitário, numa manifestação do seu poder regulatório global. Pese embora a bondade aparente do objectivo final de protecção ambiental e dos recursos comuns, como os ictiológicos, nem sempre as soluções encontradas se assemelham pacíficas, justas, eficazes e eficientes, suscitando a dúvida em torno da benignidade da extraterritorialidade e de um activismo ambiental europeu. Dessarte, abordar-se-ão os exemplos mais significativos de actuação extraterritorial verde da União Europeia e as suas principais lições, para depois avançar para a problemática específica da insustentabilidade das pescas, em particular da pesca INN, que encontra respostas em ferramentas comerciais, de certificação de captura e de rastreabilidade, numa teia unilateral complexa que suscita dúvidas quanto ao seu mérito e alcance global.

PALAVRAS-CHAVE: União Europeia; Meio ambiente; Pesca.

\section{ABSTRACT}

The European Union often resorts tounilateral mechanisms that extend its regulatory power beyond its frontiers to handle trans-national environmentalproblems, in a manifestation of its global regulatory power. Despite the apparent goodness of the final goal of environmental and common resources protection, such as ichthyological, the solutions found do not always seem to be peaceful, fair, effective and efficient, raising doubts about the benignity of extraterritoriality and European environmental activism. This text will therefore address the most significant examples of EU extraterritorial green action and its main lessons, and then move on to the specific problem of unsustainability of fisheries, in particular IUU fishing, which finds answers in commercial instruments, capture certificates and trace ability tools in a complex unilateral web that raises doubts as to its merit and global reach.

KEYWORDS: European Union; Environment; Fishing. 


\section{| INTRODUÇÃO}

A extraterritorialidade é muitas vezes vista de forma pejorativa como uma violação da soberania territorial e imposição hegemónica unilateral de standards normativos, levantando ondas de críticas pelos Estados atingidos, embora a jurisprudência Lotus admita discricionariedade na sua determinação. Todavia, em questões transnacionais como as que envolvem o ambiente ou os mercados financeiros hoje globalizados, na falta ou fragilidade de soluções internacionais, pode fazer sentido externalizar e estender os efeitos da legislação nacional ou regional com o objectivo de garantir mais efectividade, quer pela sua imposição, quer pela sua função de referencial e incentivo normativo e de alteração de condutas, incluindo empresariais.

Nas páginas que se seguem, e sem querer entrar numa discussão técnica sobre o recorte conceptual da extraterritorialidade (em que, em sentido estrito, não haveria sequer elo territorial ao ordenamento que se deveria submeter a um terceiro que impõe condutas) e das suas variações como a extensão territorial (em que já existe uma qualquer ligação - nacionalidade, territorialidade objectiva, efeitos, jurisdição universal ou princípio da protecção), assume-se a extraterritorialidade num sentido lato e fluído, tentando assim incluir medidas que procurem regulamentar comportamentos ou circunstâncias no exterior, em especial num equilíbrio entre a liberdade regulatória de Estados soberanos iguais e os interesses da comunidade internacional, mormente, no que aqui interessa, no âmbito de problemas ambientais transnacionais, máxime a pesca insustentável.

A União Europeia (UE) opta amiúde, no plano ambiental e da pesca INN (Ilegal, Não declarada, Não regulamentada), por mecanismos unilaterais (e outros multilaterais) que estendem o seu poder regulatório a condutas, presença, direitos de apropriação ou circunstâncias que ocorrem ou prevalecem fora do espaço europeu, numa manifestação do seu poder regulatório global e da sua assunção como actor maior no plano da sustentabilidade, sobretudo quando dispõe de um princípio do nível elevado de protecção ambiental'. Pese embora a bondade aparente do objectivo final de protecção ambiental e dos recursos comuns, como os ictiológicos, nem sempre as soluções encontradas se assemelham pacíficas, justas, eficazes e eficientes, suscitando a dúvida em torno da benignidade da extraterritorialidade e de um activismo ambiental europeu.

Dessarte, abordar-se-ão os exemplos mais significativos de actuação extraterritorial verde da União Europeia e as suas principais lições, para depois avançar para a problemática específica da insustentabilidade das pescas, em particular da pesca INN, que encontra respostas em ferramentas comerciais, de certificação de captura e de rastreabilidade, numa teia unilateral complexa que suscita dúvidas quanto ao seu mérito e alcance global.

Por todos, Alexandra Aragão (2006). O Princípio do Nível Elevado de Protecção e a Renovação Ecológica do Direito do Ambiente, Almedina, Coimbra. 


\section{EXEMPLOS DE EXTERRITORIALIDADE OU EXTENSÃO TERRITORIAL DO DIREITO DA UNIÃO EUROPEIA NO PLANO AMBIENTAL}

As questões ambientais, em muitos casos pela sua índole transfronteiriça e global associada à natureza de recurso comum do macrobem ambiental, com causas e efeitos difusos que não se contêm geográfica nem temporalmente, assumem-se como candidatas paradigmáticas a um tratamento jurídico extraterritorial ou de extensão territorial. Assim, no âmbito do Direito da União Europeia, podem encontrar-se vários exemplos, recordando-se de seguida quatro dos mais significativos e citados doutrinariamente2.

Os dois primeiros ${ }^{3}$ envolvem o problema ambiental por excelência, pela sua transversalidade e complexidade, a saber o sobreaquecimento do Planeta e as alterações climáticas que, pela sua dimensão global, tanto no plano das fontes como no dos seus impactos, obrigam a uma resposta coordenada e multinível e merecem aqui mais atenção da nossa parte.

A criação de soluções internacionais não basta, são necessárias políticas e medidas tomadas regional, nacional e localmente, não tanto numa lógica de descentralização, mas mais de integração policêntrica. Nessa linha, parece compreensível a ligação não só entre os sistemas de comércio de emissão existentes como o seu relacionamento com mecanismos semelhantes, permitindo a definição de um preço internacional dos Gases de Efeitos de Estufa (GEE) e uma melhor aferição dos custos do combate ao aquecimento global. A União Europeia, na sequência dos compromissos assumidos como um todo e individualmente para cada Estado-Membro, no âmbito da Convenção-Quadro das Nações Unidas para as Alterações Climáticas e, em particular, do seu Protocolo de Quioto (PQ), cedo compreende as potencialidades e os dividendos económicos e políticos da abertura do Comércio Europeu de Licenças de

2 Entre outros, Joanne Scott (20 I 4). Extraterritoriality and Territorial Extension in EU Law, The American Journal of Comparative Law, American Journal of Comparative Law, n. ${ }^{\circ}$ 62; Natalie L. Dobson (20I8). The EU's conditioning of the 'extraterritorial' carbon footprint: A call for an integrated approach in trade law discourse, RECIEL, Vol. 27, n. ${ }^{\circ}$ I; IoannaHadjiyianni (20 I7). The Extraterritorial Reach of EU Environmental Law and Access to Justice by Third Country Actors, European Papers, Vol. 27, n. ${ }^{\circ}$ 2; Tomasz Koziel (20I2). Extraterritorial Application of EU Environmental Law - Implications of the ECJs Judgment in Air Transport Association of America, The Columbia Journal of European Law Online, n. ${ }^{\circ} 19$.

3 Pode-se ainda em matéria de alterações climáticas e "extraterritorialidade" do Direito Europeu, olhar para o Regulamento 20 I5/757/UE relativo à monitorização, reporte e verificação de emissões de CO2 de transportes marítimos, alterando a Directiva 2009/I 6/CE. Em sentido mais lato, uma vez que as causas das alterações climáticas e sobreaquecimento do planeta são múltiplas, também neste âmbito se poderia referir a importação ilegal de madeira (a tratar sucintamente mais abaixo) ou os critérios de sustentabilidade dos biocombustíveis decorrentes da Directiva 2009/28/CE. 
Emissão (CELE). Desde logo, na Directiva n 2003/87/CE, na sua versão originária, prevê-se um esforço de ligação a outros regimes semelhantes, por meio de acordos internacionais, reforçado com a Directiva n² 2004/I0I/CE (DirectivaLinking), que institucionaliza a criação de pontes com o Protocolo de Quioto pela equiparação directa entre as Unidades de Redução Certificada de Emissões (URCE)45 de projectos decorrentes do Mecanismo de Desenvolvimento Limpo (MDL), estipulado no artigo $12^{\circ}$ do Protocolo de Quioto, as Unidade de Redução de Emissões (URE), provenientes do mecanismo de Implementação Conjunta (IC), consagrado no artigo $6^{\circ}$ do Protocolo de Quioto, e as licenças de emissão do Comércio Europeu de Licenças de Emissão, autorizando a transacção de créditos de redução obtidos por meio de projectos em países excluídos do Anexo 16 (i.e. sem objectivos quantificados de redução ou limitação de emissões) para o cumprimento da cobertura de emissões dos Gases de Efeitos de Estufa por parte dos operadores.

A questão climática ${ }^{7}$ tem o condão de conduzir a União Europeia à liderança do dossier ambiental (e energético) e fomentar o surgimento de um novo enquadramento jurídico-principiológico e de obrigações substantivas concretas, que se pretende estender para fora da esfera europeia. Aliás, nesta sede, o sucesso do Mecanismo de Desenvolvimento Limpo, e a sua ligação ao Comércio Europeu de Licenças de Emissão, permite a exportação das preocupações e políticas ambientais e energéticas comunitárias para os Países em Vias de Desenvolvimento (PVD) e Países Menos Desenvolvidos (PMD), num fenómeno de contágio importante para a causa climática. No entanto, o Mecanismo de Desenvolvimento Limpo representa, igualmente, o reverso da medalha, pois a criação excessiva (e até fraudulenta) de Redução Certificada de Emissões gera graves problemas de corrupção, risco moral e de desvio da estabilização climática pretendida, uma vez que, por um lado, não se

\section{Em inglês, Certified Emission Reductions (CER).}

5 No seio do MDL e associado à actividade de florestação e reflorestação, atente-se também às URCE temporárias ou URCE-T, designando uma unidade de redução certificada acordada por uma actividade de florestação ou reflorestação no âmbito do MDL, cuja validade expira no fim do período de cumprimento seguinte àquele em que foi criada; e às URCE de longa duração ou URCE-LD, designando uma unidade de redução certificada acordada por uma actividade de florestação ou reflorestação no âmbito do MDL, cuja validade expira no fim do período de contabilização para a atribuição de créditos de emissão da actividade de florestação ou reflorestação no âmbito do MDL para a qual ela foi criada.

6 Recorde-se que o Anexo I incluía os países-membros da UE à data da ratificação do Protocolo de Quioto pela União e da sua entrada em vigor.

7 Retoma-se aqui trabalho desenvolvido em Rute Saraiva (2009). A Herança de Quioto em Clima de Incerteza: Análise Jurídico-Económica do Mercado de Emissões num Quadro de Desenvolvimento Sustentado, Tese de Doutoramento, Faculdade de Direito da Universidade de Lisboa, Lisboa. 
obtém a redução física desejada das emissões poluentes, como, por outro lado, pela sua ligação ao Comércio Europeu de Licenças de Emissão, contagia-se o esforço europeu, mormente com um aumento do tecto de emissões.

Porém, para mostrar a seriedade e convicção dos compromissos assumidos, a Decisão $n^{\circ}$ 406/2009/CE limita ${ }^{8}$ o recurso a créditos resultantes de actividade de projecto, de forma a assegurar que as reduções significativas das emissões decorrem de medidas internas num esforço conjunto entre os diferentes níveis de decisão, do local ao supranacional, sendo a utilização dos mecanismos de flexibilidade apenas complementar. Nesse sentido, limita-se a utilização anual, pelos Estados-Membros, de créditos de projectos de redução em países terceiros até uma quantidade que represente 3\% das emissões de Gases de Efeitos de Estufa de cada Estado-Membro não abrangidas pela Directiva n 2003/87/CE, em 2005, ou noutros Estados-Membros, até à celebração de um futuro acordo internacional sobre as alterações climáticas. Os Estados-Membros podem, se autorizados, transferir para outros a parte não utilizada dessa quantidade. No entanto, os Estados-Membros com um objectivo de redução das emissões, ou um objectivo de aumento, de 5\% no máximo, referido no Anexo II, que constem do Anexo III, podem usar por ano, além dos créditos acima referidos, créditos adicionais correspondentes a $1 \%$ das suas emissões verificadas em 2005 no contexto de projectos em Países Menos Desenvolvidos (PMD) e em Pequenos Estados Insulares em Desenvolvimento (PEID) em consequência do cumprimento de uma das quatro condições seguintes:

- $\quad$ nos casos em que, segundo a avaliação de impacto da Comissão, os custos directos do pacote global excedam 0.70\% do Produto Interno Bruto;

- $\quad$ nos casos em que exista um aumento de, pelo menos, 0.1\% do Produto Interno Bruto entre o objectivo de facto aprovado em relação ao Estado-Membro em causa e a estimativa da relação custo-eficácia de acordo com a avaliação de impacto da Comissão;

- $\quad$ nos casos em que mais de 50\% do total de emissões do Estado-Membro em causa abrangidas pela presente decisão correspondam a emissões relacionadas com os transportes; ou

- $\quad$ nos casos em que o Estado-Membro em causa tenha um objectivo de energia renovável, para 2020 superior a 30\% referido na Directiva do Parlamento Europeu e do Conselho, relativa à promoção da utilização de energia proveniente de fontes renováveis. Nessa situação, enquadra-se, entre outros, Portugal, não só devido à fatia de energias renováveis, mas também porque se lhe possibilita um aumento de $1 \%$ das emissões em relação a 2005.

8 Note-se que a proposta apenas limita, e não afasta, o recurso às actividades de projecto, o que revela realismo em matéria de custos e uma preocupação com a obrigação de ajuda ao desenvolvimento sustentado dos PVD. 
Nessa linha, e diante da intenção de apoiar os Países em Vias de Desenvolvimento e de conseguir alcançar maior eficiência, a União continua empenhada na melhoria do Mecanismo de Desenvolvimento Limpo e no reconhecimento de créditos, com o reforço da garantia de projectos que representem reduções reais, verificáveis, adicionais e permanentes, que constituam uma mais-valia significativa em termos de desenvolvimento sustentado e com um impacto ambiental ou social reduzido e que garantam uma repartição equitativa dos projectos. Ainda assim, no âmbito da Decisão n 406/2009/CE, reconhece-se, todavia, que, nos Países Menos Desenvolvidos, foi muito reduzido o número de projectos realizados no âmbito do Mecanismo de Desenvolvimento Limpo. Ora, na procura de uma repartição mais equitativa, em especial por meio da Aliança Global9, garante-se a aceitação de créditos de projectos iniciados após o período 2008-20 I 2 em Países Menos Desenvolvidos, a categorias de projecto elegíveis para utilização no Comércio Europeu de Licenças de Emissão para essa mesma fase. Essa aceitação deverá manter-se até 2020 ou até à celebração de um acordo com a União, conforme o que ocorrer primeiro. Além disso, para proporcionar mais flexibilidade e promover o desenvolvimento sustentado nos Países em Vias de Desenvolvimento, os Estados-Membros poderão utilizar créditos adicionais de projectos mediante acordos celebrados pela União com países terceiros. Note-se ainda que a faculdade de os Estados-Membros continuarem a recorrer aos créditos de Mecanismo de Desenvolvimento Limpo importa para Ihes garantir a existência de um mercado após 2012. Contudo, sublinhe-se mais uma vez, o texto do acordo de partilha intracomunitária só permite, uma vez celebrada uma futura convenção para substituir o Protocolo de Quioto, a aceitação de créditos de países que tenham ratificado esse acordo e estejam sujeitos a uma abordagem comum. Visa-se, dessa forma, incentivá-los à adesão do novo instrumento.

9 Comunicação da Comissão ao Conselho e ao Parlamento Europeu, de 18 de Setembro de 2007, " Criar uma Aliança Global contra as Alterações Climáticas entre a União Europeia e os Países em Desenvolvimento Pobres e mais Vulneráveis às Alterações Climáticas", COM (2007) 540 final. Ver também as Conclusões do Conselho sobre uma Aliança Global contra as Alterações Climáticas entre a União Europeia e os países em desenvolvimento pobres e mais vulneráveis às alterações climáticas - Conselho "Assuntos Gerais e Relações Externas", a 20 de novembro de 2007. A ideia de uma Aliança Global para fazer face às alterações climáticas nasce, em Junho de 2007, da proposta do Livro Verde sobre a Adaptação às Alterações Climáticas na Europa que contém um pilar sobre a integração nas acções externas da UE, exortando o aprofundamento do diálogo e cooperação neste domínio entre a UE e os PVD. Neste sentido também já apontavam a Comunicação da Comissão ao Conselho e ao Parlamento Europeu, "As Alterações Climáticas no Contexto da Cooperação ao Desenvolvimento", COM (2003) 85 final - Diário Oficial C/2004/76, e as Conclusões do Conselho "Assuntos Gerais e Assuntos Externos", de 22 de novembro de 2004, sobre as alterações climáticas no contexto do apoio ao desenvolvimento, com o Plano de Acção 2004-2008. 
A experiência europeia revela, igualmente, no âmbito da extensão territorial do cumprimento das obrigações decorrentes do Comércio Europeu de Licenças de Emissão, algumas pistas interessantes quanto ao contributo da interligação entre mecanismos. Por um lado, o elo com os dois mecanismos de flexibilidade (IC e MDL) confere ao mercado uma nova dimensão e dinâmica, com o preço dos seus créditos a influenciar não só as decisões dos agentes económicos, mas igualmente as perspectivas de evolução do valor das licenças. No entanto, para o regime funcionar correctamente, importa bloquear fenómenos de dupla contagem ou de inundação do mercado com esses títulos que podem destruir os incentivos ao desenvolvimento de medidas internas, fazendo com que os maus activos expulsem os bons. Por outras palavras, importa, até pelo princípio da adicionalidade retirado do Protocolo de Quioto, pela própria credibilidade do Comércio Europeu de Licenças de Emissão ${ }^{10} \mathrm{e}$ para evitar distorções entre os sectores do CELE e não CELE" ', estabelecer um limite quantitativo ao número de créditos "externos" ao sistema que podem ser adquiridos (concreteceilings) $)^{12}$.

No entanto, a equivalência directa entre os diferentes activos potencia situações de desequilíbrio, visto que alguns dos créditos são conseguidos quase sem esforço, facto que tem implicações económicas e ambientais significativas: económicas porque, ao serem mais atractivos, reduzem a preferência e procura de licenças do Comércio Europeu de Licenças de Emissão, fazendo diminuir o seu valor e descarnando, em consequência, o mercado de emissões e a inovação e desenvolvimento tecnológicos ${ }^{13}$; ambientais, porque, pela sua facilidade, não permitem criar uma cultura de respeito e de desenvolvimento ambiental, potenciando um cenário de risco moral, além de que nem todos os projectos que concedem créditos geram o

10 DEFRA (2007). Analysis Paper on EU Emissions Trading Scheme Review Options,Londres, I 5.

"I R. Schüle e W. Sterk (2008). Options and Implications of Linking the EU ETS with other Emissions Trading Schemes, European Parliament, DG Internal Policies of the Union, Policy Department Economic and Scientific Policy, 20.

12 P. Criqui e L. Viguier (2000). Régulation des Marchés de Droits D’Emission Négociables Pour le $\mathrm{CO}_{2}$ Une Proposition de Plafonds pour les Quantités et pour les Prix, Institut d'Economie et de Politique de l'Energie, Cahier de Recherche, n. ${ }^{\circ}$ 18, 4 ss.

13 Ligando-se, por exemplo, dois sistemas com preços de carbono diferentes, o preço das licenças será mais alto do que o estabelecido anteriormente num dos casos e inferior no outro. Deste modo, a procura no sistema que tinha um preço mais elevado e a oferta do sistema que apresentava um preço mais baixo beneficiam com o novo preço. Ao contrário, os compradores do programa com preços mais baixos e os vendedores do programa com preços mais altos ficam a perder, revelando uma alteração na distribuição das rendas mesmo se a ligação trouxer benefícios económicos líquidos em termos totais. Contudo, a ligação pode evidenciar divergências no tratamento de agentes económicos similares e ajudar, assim, a corrigir eventuais distorções concorrenciais identificadas. 
mesmo benefício ecológico, podendo acabar por favorecer os menos eficazes no plano ambiental. ${ }^{14}$ A esse respeito, muitas vozes se levantam para alertar para projectos de Mecanismo de Desenvolvimento Limpo demasiado laxistas e com duvidosas características de adicionalidade, que servem, a mais das vezes, para largas transferências para a China e Índia, criando ou reforçando distorções regionais ${ }^{15}$. Ademais, a abertura a outros activos possibilita a importação de novos problemas para o regime receptor com perda de controlo sobre o próprio mecanismo ${ }^{16}$. Dessa forma, as críticas que vêm sendo dirigidas ao Mecanismo de Desenvolvimento Limpo e à IC são contagiadas ao Comércio Europeu de Licenças de Emissão, gerando potenciais focos de resistência e de desequilíbrio. Mais, se não existirem garantias quanto à fiscalização e sanção pelo incumprimento num dos sistemas ligados, a desconfiança pode minar o funcionamento do mercado, conduzindo mesmo a uma corrida para o fundo com custos ambientais significativos. Em suma, a fragmentação entre diversos mercados e níveis de actuação diferentes podem fragilizar todo o esforço desenvolvido com a criação de distorções e ineficiências. ${ }^{17}$

Acresce a questão da natureza jurídica dos vários direitos de poluir e da sua compatibilização, designadamente quanto ao seu tratamento em termos tributários, com eventuais impactos na estrutura do mercado. Menos problemática será a ligação se houver, pelos menos no plano formal, uma total fungibilidade entre os direitos a trocar, seja através de um vínculo bilateral, seja através de acordos multilaterais abertos $^{18}$. Ainda hoje, nos vários níveis políticos de decisão, tem-se fugido a esta problemática, esperando talvez que se resolva no próprio mercado ou através de instituições como a tradição ou a autoridade.

Com efeito, o artigo I I ${ }^{\circ}$-A decorrente da Directiva Linking estipula que os Estados-Membros emitirão uma licença de emissão, que é imediatamente devolvida, em troca de uma Unidade de Redução Certificada de Emissões ou Unidade de Redução

14 J. Jaffe e R.N. Stavins (2008). Linkage of Tradable Permit Systems in International Climate Policy Architecture, NBER, Working Paper n. ${ }^{\circ}$ |4432, Cambridge, MA, I I; J. Chevallier e N. Raffin (2008). Linking Emissions Trading Schemes: An Assessment with Regard to Environmental Efficiency.

15 J. Jaffe e R.N. Stavins (2008). I I; J. de Sépibus (2008). Linking the EU Emissions Trading Scheme to JI, CDM and Post-20I 2 International Offsets. A Legal Analysis and Critique of the EU ETS and the Proposals for its Third Trading Period, NCCR Trade Regulation, Working Paper n. ${ }^{\circ}$ 2008/I 8, 24; M. Tatsutani e W.A. Pizer (2008). Managing Costs in a U.S. Greenhouse Gas Trading Program. A Workshop Summary, RFF, Discussion Paper n. ${ }^{\circ} 08-23,1$ I - 12.

16 J. Jaffe e R.N. Stavins (2008). I I.

17 Nesse sentido, T. James e P. Fusaro (2006). Energy and Emissions Markets. Collision or Convergence?, Wiley, Singapura, 122.

18 IETA (2006). Linking the EU ETS with Emerging Emissions Trading Schemes, Toronto e Genebra. 
de Emissões detida pelo operador no seu registro nacional. $\bigcirc$ objectivo do legislador, nesta situação, parece ser, além da ligação directa entre mecanismos, diminuir os custos de transacção com a aceitação daqueles créditos e a sua transformação numa licença de emissão. Assim, em vez de uma multiplicação de "direitos" dentro do Comércio Europeu de Licenças de Emissão, apenas passam a circular licenças de emissão. Esta aparente simplificação permite ainda aos operadores procurarem o meio menos oneroso (e mais eficiente) para cobrir as suas obrigações. No entanto, esta susceptibilidade esconde vários problemas que podem, ao contrário do que o legislador pretende, destabilizar e onerar o mercado europeu de emissões.

Em primeiro lugar, equiparam-se três "direitos" (Licenças de Emissão, Unidades de Redução Certificada de Emissões e Unidades de Redução de Emissões) com regimes e conteúdos jurídicos diferentes entre si. Em segundo lugar, a transformação em licença de um determinado Estado-Membro (com a sua própria natureza jurídica) vai conduzir a Unidade de Redução Certificada de Emissões e a Unidade de Redução de Emissões transfiguradas de forma diferente consoante o Estado-receptor. Estas duas questões abrem inevitavelmente as portas a distorções. Na senda de minimizar os seus custos, os operadores procuraram os meios mais vantajosos. Essa foi, aliás, a principal motivação por trás da Directiva Linking. No entanto, no plano internacional, verifica-se que muitos dos projectos associados ao Mecanismo de Desenvolvimento Limpo (MDL) e à Implementação Conjunta (IC) que possibilitam a atribuição de créditos se revelam menos onerosos do que a compra de licenças de emissão. Dessarte, embora haja determinações para o número de Unidades de Redução Certificada de Emissões e Unidades de Redução de Emissões a utilizar dentro do espaço europeu, a nível nacional e de instalação, a tendência será a de adquirir preferencialmente esse tipo de crédito, sobretudo quando existe uma equivalência com as licenças de emissão e não se verifica uma concorrência com Estados não comunitários para a aquisição de Unidades de Redução Certificada de Emissões e de Unidades de Redução de Emissões ${ }^{19}$. Com a abundância destes créditos no mercado internacional, o Comércio Europeu de Licenças de Emissão fica assim exposto não só às vicissitudes desse sistema como a uma concorrência mais barata que pode corroer internamente o mecanismo europeu com a diminuição do preço das licenças comunitárias de emissão. Mais, a entrada dessas unidades far-se-á pelo Estado-Membro com a natureza e regime jurídicos, contabilísticos e financeiros mais favoráveis, até porque a questão da sua natureza não se encontra resolvida em termos do conjunto europeu (e nacional, acrescentar-se-ia). As empresas desse Estado passam, nestes moldes, a funcionar como verdadeiras intermediárias de licenças de emissão, distorcendo-se, portanto, o espírito do sistema. Em última análise, podem mesmo passar a deter poder de mercado embora com a limitação dos mercados contestáveis e do preço das

19 P. Criqui e A. Kitous (2003). Impacts of Linking II and OMM Credits to European Emission Allowance Trading Scheme (KPI-ETS), Kyoto Control Implementation, 13. 
"tradicionais" licenças de emissão. A este respeito, as modificações introduzidas pela Directiva Linking deixam algumas brechas susceptíveis de potenciar estes problemas.

Boa parte do sucesso da interligação reside portanto no desenho cuidadoso do sistema e do seu quadro institucional, reduzindo fenómenos de segmentação e de aumento dos custos de transacção e de harmonização que podem gerar ineficiências perigosas. Mais, convém não menosprezar as implicações conceptuais resultantes da abertura/ligação. Designadamente, numa lógica de convergência para uma maior harmonização, a concorrência entre modelos de mercados de emissão cria uma dinâmica de afirmação para definir qual a estrutura de referência em torno da qual se reorganizam. $O$ vencedor passa a exportar a sua construção e regras, enquanto que os outros incorrem em custos de ajustamento.200ra, se os mecanismos internacionais de flexibilidade do Protocolo de Quioto começam por se impor, influenciando a edificação concreta do Comércio Europeu de Licenças de Emissão, a pujança deste último no âmbito dos mercados para os Gases de Efeitos de Estufa joga crescentemente a seu favor, incluindo pela sua abertura e extensão territorial.

Resumindo, no plano da extraterritorialidade, ou mais propriamente de extensão territorial, a conexão territorial estabelecida prende-se com os direitos carbónicos extra-comunitários serem usado no âmbito do Comércio Europeu de Licenças de Emissão para o cumprimento das obrigações assumidas, portanto numa lógica de conduta mas também de estado de propriedade, apresentando-se, todavia, esta possibilidade condicionada (salvo para os casos envolvendo Países Menos Desenvolvidos - no âmbito do Mecanismo de Desenvolvimento Limpo) à existência de um acordo bilateral com União ou de um acordo internacional específico. Ademais, esta solução, natural quanto a um problema ambiental global, se pretende, por um lado, promover extraterritorialmente a consciência ambiental (e energética) e encontrar as soluções mais eficientes e económicas, por outro, potencia riscos, brechas e incongruências no Comércio Europeu de Licenças de Emissão.

O segundo exemplo de extraterritorialidade, ainda dentro da questão climática e do seu necessário tratamento transversal, prende-se com a Directiva n 2008/I 0 I/CE, com a introdução do sector da aviação no Comércio Europeu de Licenças de Emissão. Seguindo a lógica da Directiva n 2003/87/CE, a União pretende envolver os grandes emissores, desta vez difusos, de Gases de Efeitos de Estufa. Assim, estabelece a entrega de licenças de emissão por parte das companhias aéreas, tendo em conta toda a duração do voo, mesmo a parte fora espaço europeu. Dessa forma, a conexão territorial envolve a conduta e presença, considerando todos os voos com partida ou chegada ao espaço da União Europeia. No entanto, prevê-se a isenção da obrigação de entrega de licenças, se o país terceiro de partida adoptar medidas equivalentes ao Comércio

20 J.F. Green (2008). The Regime Complex for Emissions Trading: The Role of Private Authority, Princeton University, Paper presented to the International Studies Association San Francisco, CA, 2. 
Europeu de Licenças de Emissão para redução de Gases de Efeitos de Estufa nos voos e aceita-se a alteração daDirectiva se vier a ser alcançado um acordo internacional para redução de emissões de Gases de Efeitos de Estufa de aviação.

Nesse âmbito, e diante das queixas de companhias não europeias, o Tribunal de Justiça da União Europeia (TJUE) foi chamado a se pronunciar no caso C-366/l 0 Air Transport Association of America and Others. ${ }^{21} \bigcirc$ Tribunal de Justiça da União Europeia recusa a violação do Direito consuetudinário internacional devido à extensão sobre o Alto Mar e vem reconhecer um vínculo territorial (e jurisdição ilimitada) com base nos efeitos ambientais, o que suscita críticas e dúvidas sobre um possível imperialismo ambiental europeu ligado à sua liderança política nessa matéria ${ }^{22}$, e na ligação da conduta com território. A esse respeito, o Tribunal defende que a Directiva não regulamenta o comportamento para além do espaço comunitário, constituindo ao invés um regulamento do transporte aéreo aplicável após o desembarque num dos aeroportos da União Europeia. Também o advogado geral considera a existência de uma ligação entre a conduta e o território de um Estado-Membro da União Europeia como um argumento incontornável na resolução da contestação da extraterritorialidade. No entanto, e como se começou por apontar na introdução, essa justificação não é suficiente, já que, para lá de um sentido muito estrito, uma jurisdição pode ter uma dimensão extraterritorial quando relacionada a eventos que ocorrem para lá das fronteiras de um país. Por outras palavras, a tese do Tribunal é de que o Direito europeu neste caso não é aplicado extraterritorialmente mas tem implicações extraterritoriais, recorrendo, por um lado, à doutrina dos efeitos e, por outro, à da territorialidade objectiva por meio do contacto com os aeroportos europeus. Pena é que o Tribunal de Justiça da União Europeia, que tem algum cuidado em construir o seu caso com base no Direito Internacional, não tenha aproveitado para aprofundar conceptual e dogmaticamente o conceito de extraterritorialidade e ligá-lo e distinguilo nomeadamente da ideia de extensão territorial ou ainda para averiguar um pouco mais a compatibilidade da Directiva com o Direito consuetudinário e convencional

2l Sobre esta decisão, ver nomeadamente B. Havel e J. Mulligan (20 I2). The Triumph of Politics: Reflections on the Judgment of the Court of Justice of the European Union Validating the Inclusion of Non-EU Airlines in the Emissions Trading Scheme, Air and Space Law, Vol. 37, n. ${ }^{\circ}$ 3; T. Koziel (20 I 2).; Geert de Baere e Cedric Ryngaert (20 I 3). The ECJ's Judgment in Air Transport Association of America and the International Legal Context of the EU's Climate Change Policy, European Foreign Affairs Review, Vol. 18, n. ${ }^{\circ} 3$.

22 T. Koziel (20 I 2). 5; G. de Baere e C. Ryngaert (20 I3). 400-40 I. Veja-se que não é possível determinar se os efeitos das alterações climáticas na Europa apenas se relacionam com os voos que partem ou aterram no espaço comunitário. Ou seja, qualquer voo, mesmo não sobrevoando ou entrando no espaço europeu pode, pelas suas emissões, causar impactos na UE, pelo que o recurso à tese dos efeitos implica, em consequência e em última análise, a defesa de uma jurisdição universal que muito esticaria a extraterritorialidade. 
internacional, em particular o Protocolo de Quioto, a Convenção de Chicago ou o Acordo bilateral Open Skies, e, portanto, com os direitos soberanos dos Estados sobre o espaço aéreo. Veja-se que o Tribunal de Justiça da União Europeia advoga alguma insuficiência do Direito costumeiro quanto à submissão exclusiva da aeronave que sobrevoa o Alto Mar ao Estado de registro. ${ }^{23}$

O terceiro exemplo de extraterritorialidade (ou melhor, de extensão territorial) reconduz-se ao Regulamento n 995/2010/UE, referente à importação de madeira (e derivados), proibindo a entrada no espaço europeu de madeira ilegal à luz do Direito de país terceiro, estabelecendo como conexão territorial com o ordenamento jurídico comunitário a conduta de comercialização no espaço da União Europeia. Essa interdição apresenta, porém, excepções na sua imposição. Por um lado, se o comércio da madeira for licenciado à luz da Convenção sobre o Comércio Internacional das Espécies da Fauna e da Flora Selvagens Ameaçadas de Extinção (CITES). Por outro, é permitido para determinadas espécies cumprir standards de devida diligência (duediligence) do Regulamento n 995/20 I0/NE e do Regulamento n² $2173 / 2005 / C E$, que obriga a transparência na supplychain, assim como a manutenção de um sistema de duediligence monitorizado por uma organização reconhecida pela União. Por fim, não se apresenta como necessária a sujeição a estes standards se o importador se conformar com standards equivalentes estabelecidos num acordo de Parceria Voluntária (PA) entre o Estado terceiro e a União Europeia.

Por fim, em quarto lugar, saliente-se a Directiva n 2012/I9/NE, relativa à exportação de resíduos/ixo eléctrico e electrónico, que regulamenta o tratamento adequado dos resíduos e metas de recuperação para produtores, quer sejam empresas estabelecidas na União Europeia ou empresas de países terceiros que vendem para a União Europeia, fixando como conexão territorial a conduta de produção na União e para metas da União. De acordo com a Directiva, as operações de tratamento em relação aos resíduos gerados na União Europeia, realizadas fora desta podem contar para a meta de recuperação do produtor se a operação de tratamento tiver lugar em condições equivalentes às exigidas pela legislação europeia.

Desses casos, podem-se retirar algumas lições de exterritorialidade/extensão territorial do Direito da União Europeia no plano ambiental, extensíveis, com as adequações necessárias, a outras áreas. ${ }^{24}$

Por um lado, a extensão territorial visa promover alteração de comportamento ou jurídica em país terceiro e/ou internacionalmente, ou seja servir de exemplo e de referencial normativo (de qualidade), numa exportação de valores e sistema, não necessariamente puramente europeus mas aceites no plano internacional. Dessarte,

23 T. Koziel (20।2). 6-7; G. de Baere e C. Ryngaert (2013). 395-398.

24 J. Scott (20|4). II 4 ss. 
pretende funcionar como catalisador normativo para países terceiros e de negociações e cooperação multilaterais.

Assim, quer-se incentivar a melhoria de standards e performance, sobretudo no âmbito de importações (ou seja, jogando com a dimensão económica e de possibilidade de abertura dos mercados de países terceiros à União Europeia) e modificar a organização, governance e actividade/operações de empresas, países e até instituições regionais e globais.

No fundo, observa-se, não tanto em primeira linha, certa preocupação com interesses (económicos e políticos) europeus, mas sim, pelo menos aparentemente, com questões de interesse global, como se fosse uma missão altruísta que realça a dimensão ética da actuação europeia na questão climática e ambiental, mas também um reconhecimento de que os comportamentos de terceiros têm cada vez mais influência e impacto na União Europeia, mormente em termos de qualidade de vida e de mercado.

Dos exemplos acima apresentados, resulta igualmente o esforço de a União basear a extensão territorial do seu enquadramento jurídico nas orientações internacionais e no Direito internacional, sobretudo porque se trata de problemas transnacionais. Dessarte, observa-se um exercício de fomentar maior efectividade e alcance à soft law ou alargar o âmbito geográfico de normas só vinculativas para um número reduzido de partes. Não existindo base internacional, procura-se fomentar a negociação e soluções internacionais ou partir das normas europeias como âncora. Assim, os casos de unilateralidade envolvem a criação de obrigações autónomas da União Europeia na ausência de normas internacionais, seja porque aquelas são consideravelmente mais detalhadas e/ou mais exigentes do que as correspondentes medidas internacionais, seja porque criam um papel para a União Europeia no fomento e aplicação da legislação internacional. ${ }^{25}$

Outra lição importante reside na flexibilidade das soluções extraterritoriais que atendem geralmente às condições concretas do Estado terceiro, nomeadamente solicitando medidas equivalentes. Mais, aposta-se em incentivos com recompensas diferenciadas (exemplo: apenas uma licença de entrada para o mercado europeu, moratória na aplicação da Regulação dos Gases de Efeitos de Estufa/Aviação, de modo a potenciar negociações bilaterais e internacionais ou soluções nacionais equivalentes).

Por outras palavras, a abordagem extraterritorial do Direito da União Europeia assume-se diferente, por exemplo, da tradicional opção americana. Veja-se, nomeadamente, na área ambiental, o caso Turtle-Shrimp ${ }^{26}$, em que os Estados Unidos não procurou

\section{J. Scott (20|4). II3.}

26 No âmbito da OMC/GATT, Turtle-Shrimps India et al. v U.S. (1998). O Painel considera invocação americana de artigo XX injustificável (sem aplicar o teste). O Órgão de Apelo mantém decisão embora discorde da abordagem do Painel mas observa-se uma separação do Direito do ambiente do Direito do comércio, deixando a melhoria dos standards ambientais para futuras negociações. 
negociação prévia, nem base no Direito internacional e impôs os standards americanos (e não medidas equivalentes). Posto de outra forma, a União Europeia, em termos de extraterritorialidade, parece preferir interdependência, responsabilidade e unilateralismo contingente, em vez de hegemonia, proteccionismo e unilateralidade cega.

\section{O PROBLEMA DAS PESCAS E A PESCA INN}

A questão das pescas enquadra-se na famosa Tragédia dos Comuns, que afecta os recursos comuns sem verdadeira definição de direitos de apropriação. Devido às suas características de livre acesso e natureza emulativa, observa-se uma sobre-exploração e subprodução do recurso, provocando uma corrida para o fundo, com a sua exaustão, agravada por uma relação predador-presa viciada pela hegemonia e apetite humanos, não permitindo, pois, a recuperação das espécies. Trata-se de um problema transnacional em que os sistemas tradicionais de monitorização por parte do Estado costeiro ou de bandeira falham, como aliás evidencia a monitorização dos bancos piscícolas na busca de uma captura sustentável.

Com efeito, existem hoje modelos dinâmicos e cada vez mais complexos, usados por exemplo pela União Europeia, para medir e calcular a pesca sustentável, tendo em atenção diversas variáveis (como a qualidade das águas) para além da morbilidade e renovação natural do pescado. Ora, apesar da sua utilização na definição (e fiscalização) de direitos de pesca, observa-se que, nos ciclos sucessivos de recuperação das espécies, o seu número global vem decrescendo lenta mas consistentemente, o que indicia,de forma clara, uma prática de pesca INN.

As principais soluções testadas actualmente para combater a pesca INN envolvem, grosso modo, duas alternativas: i) medidas restritivas do comércio, também conhecidas como "sanções comerciais", e promulgadas por um ou mais Estados; e ii) esquemas de certificação de captura, com duas variantes específicas principais, a saber esquemas de documentação comercial e esquemas de certificação de captura.

Várias organizações regionais de gestão das populações de atum, por exemplo, preferem os esquemas de documentação comercial, que revelam a capacidade de detectar operações de navios de conveniência e deter ou, pelo menos, desincentivar o comércio de espécies específicas de países de bandeira de conveniência. Todavia, essa medida provocou alteração na pesca de atum INN com mais de 95\% das operações desse tipo a serem perpetradas por embarcações de pesca legalmente registradas e licenciadas, que realizam actividades ilegais, como a declaração incorrecta ou subnotificação de capturas, que podem ser eliminadas eficazmente pela implementação de um sistema de certificados de captura. ${ }^{27}$

27 Gilles Hosch (2016). Trade Measures to Combat IUU Fishing: Comparative Analysis of Unilateral and Multilateral Approaches, International Centre for Trade and Sustainable Development, Issue Paper, Geneva, vii. 
Os sistemas multilaterais de certificados de captura estabelecem um mecanismo de certificação pelo Estado de bandeira da legalidade da captura das espécies previstas. Quando bem construídos e implementados ao longo da cadeia produtiva, são eficazes e simples de fiscalizar, evitando sub-notificações e relatórios lacunosos. $\bigcirc$ seu sucesso empírico traduz-se quer na quebra de detecção de incumprimentos, quer na recuperação dos stocks de peixe. A componente económica ajuda também a explicar a sua eficácia: apesar de custos económicos e sociais iniciais na sua efectivação, provoca a diminuição do preço do produto ilegal, visto que este não pode ser trazido legalmente para o mercado, desincentivando, portanto, a pesca INN. ${ }^{28}$

No plano europeu, que já ensaiara a extraterritorialidade no plano das pescas com o Regulamento n 3094/86/CEE, avaliado no Caso Poulsenand Diva Navigation pelo Tribunal de Justiça da União Europeia, o seu enquadramento jurídico resulta actualmente dos Regulamentos n 1005/2008/CE, relativo à pesca INN, n I006/2008/ $C E$, relativo às autorizações para as actividades de pesca exercidas pelos navios de pesca comunitários fora das águas comunitárias e ao acesso de navios de países terceiros às águas comunitárias, e n 468/2010/UE da Comissão, que estabelece a lista da União Europeia de navios que exercem atividades de pesca INN. Prevê-se, dessarte, um mecanismo unilateral de certificação de captura ao qual acrescem medidas restritivas do comércio, com um sistema de "cartões amarelos" (identificação de países não cooperantes) e de "cartões vermelhos" (proibição de importações). De forma simples, o Regulamento $n^{\circ}$ 1005/2008/CE, nos seus artigos $2^{\circ} n^{\circ} 2$ alínea a), e $12^{\circ} n^{\circ} 3$, determina que as actividades de pesca que resultam em produtos da pesca exportados para a União Europeia, independentemente de onde sejam efectuadas, sejam levadas a cabo em conformidade com os requisitos de legalidade do Estado de pavilhão da embarcação e de acordo com as normas internacionais de conservação e gestão.

Nos termos do Direito da União Europeia, e considerando critérios formais, procedimentais e substantivos, presume-se que um navio de pesca está envolvido em pesca INN, nomeadamente se:

i. não possuir uma licença de pesca válida;

ii. não cumprir as suas obrigações de registro ou declaração dos dados de captura ou dados conexos;

iii. falsificar ou dissimular as respectivas marcas, identidade ou número de registro ou elementos de prova relevantes para uma investigação;

iv. pescar numa área de reserva, durante um período de defeso, sem quota ou após o esgotamento de uma quota ou para além de uma profundidade proibida;

v. pescar espécies não autorizadas;

${ }^{28}$ G. Hosch (20|6). vii. 
vi. $\quad$ utilizar artes de pesca proibidas ou não conformes;

vii. obstruir a atividade dos inspetores;

viii. levar para bordo, transbordar ou desembarcar pescado de tamanho inferior ao regulamentar;

ix. participar em atividades com navios que constem da lista de navios INN;

x. exercer atividades de pesca na zona de competência de uma Organização Regional de Gestão das Pescas (ORGP), sem respeitar as medidas de conservação e de gestão dessa organização e se estiver registrado num país que não seja Parte nessa organização, ou se não cooperar com essa mesma organização;

xi. for um navio apátrida.

O Regulamento n 1005/2008/CE estabelece uma série de medidas para impedir que os produtos da pesca INN entrem no mercado da União, designadamente por meio de inspecções portuárias.

De outro modo, e como medida central dissuasória, prevê-se a criação e uso no acesso e no mercado europeu de um sistema unilateral de certificado de captura que pretende garantir que os produtos importados para a União Europeia não provêm da pesca INN. São emitidos pelo Estado de pavilhão e acompanham os produtos da pesca ao longo da cadeia de abastecimento, a fim de permitir a verificação contínua, o que indicia uma extensão territorial do Direito europeu, em especial nos termos dos artigos $12^{\circ}$ e $14^{\circ}$ do Regulamento $n^{\circ}$ 1005/2008/CE, respectivamente sobre importações directas e indiretas, e $6^{\circ}$ do Regulamento n $1010 / 2009 / C E$ sobre certificados simplificados (pesca artesanal). Todavia, este mecanismo unilateral apresenta falhas e dificuldades sérias na sua aplicação e cumprimento. Com efeito, baseia-se num formulário em papel sem registro central de dados, o que, no final, prejudica uma rastreabilidade eficaz e verificável e, portanto, a exclusão de produtos extraídos ilegalmente de fluxos de fornecimento certificados. Ademais, devido à unilateralidade, os produtos (derivados) da pesca podem circular por grande parte da cadeia de abastecimento sem estarem cobertos por certificados, além de que, ao contrário dos sistemas multilaterais que cobrem e protegem stocks inteiros, aqui apenas o fazem parcialmente em muitos casos. ${ }^{29}$

Acrescente-se, contudo, à semelhança dos exemplos ambientais citados no ponto anterior, que o enquadramento europeu de certificação aceita a equivalência de mecanismos de certificação semelhantes, sejam eles multilaterais ou nacionais. Por exemplo, quaisquer produtos abrangidos pelos certificados de organizações regionais de gestão das pescas (RFMO - Regional fisheries management organisations) e importados para a União Europeia estão isentos da obrigação de fornecer certificados de

29 G. Hosch (2016). vii-viii, 29-30. 
captura da União Europeia, tal como países como a Noruega, o Canadá ou a Nova Zelândia, que desenvolveram sistemas nacionais de certificação para responder aos requisitos europeus, fornecendo, pois, o mesmo grau de garantia.

Como se adiantou, atendendo à presunção de actividades de pesca INN, a Comissão Europeia identificará os navios de pesca relativamente aos quais as informações obtidas são suficientes para presumir a sua participação em pesca INN; notificará os Estados de pavilhão (pertencentes à União Europeia e países terceiros); transmitirá as informações a todos os países da União Europeia e elaborará uma lista de navios que exercem pesca INN (embora com medidas de salvaguarda e mecanismos de recurso para garantir um tratamento equitativo dos navios e dos países em questão).

A Comissão nomeará também os países fora da União Europeia não cooperantes no âmbito da luta contra a pesca INN, enquanto Estado de pavilhão, Estado do porto, Estado costeiro ou Estado de comercialização. Depois de um processo dialogante, e não público, com consultas bilaterais e incentivador (mole) de alinhamento de interesses que não chegue, enfim, a um acordo bem-sucedido sobre as práticas alegadamente ilegais, os Estados tidos como prevaricadores farão parte de uma lista "negra" (cartão vermelho) após uma pré-identificação que funciona como um cartão amarelo. Esta lista, pese embora seja uma sanção soft ante sua natureza de norma social, acaba por produzir efeitos devido à vergonha e mal-estar associados à situação e sinalização dada em termos de (má) imagem do Estado prevaricador para os outros Estados e para o mercado. Em suma, nenhum país (tal como nenhum operador) anseia por se ver retratado negativamente perante os seus pares, além de que lhe é dificultado o acesso a novos mercados, pelo que tenderão, quanto mais não seja por razões económicas subjacentes, a tomar medidas de correcção. Os dados empíricos revelam que essa medida tem levado alguns países a melhorar os seus enquadramentos jurídicos e governança das pescas, mas não é possível apurar se, no final, tal se traduz numa redução da pesca INN. Ademais, os critérios utilizados para essa identificação de maus comportamentos parecem, porém, algo opacos e dúbios, sendo estranho constatar a falta de coincidência entre as listas europeia e americana. ${ }^{30}$

Os países da União Europeia devem aplicar sanções (comerciais) eficazes, proporcionadas e dissuasoras, com critérios justos e transparentes, às pessoas singulares ou coletivas que exerçam actividades de pesca INN. Estas serão tão mais eficazes quanto maior for a dependência dos operadores/países do acesso ao mercado europeu. Todavia, as sanções apenas estão previstas para pesca por navios de Estados-Membros ou pescas em águas dos Estados-Membros ou, ainda, no caso de infracções graves detectadas no território ou nas águas europeias, mas que tenham sido cometidas no Alto Mar ou dentro da jurisdição de um país terceiro e que estejam a ser sancionadas nos termos do $n^{\circ} 4$ do artigo $11^{\circ}$.

${ }^{30}$ G. Hosch (20|6). viii. 
Resumindo, as medidas comerciais da União Europeia só se aplicam aos Estados na sua capacidade de Estados de bandeira, pelo que na sua qualidade de Estados do porto ou de comercialização, mesmo participando no branqueamento de produtos INN, não podem ser visados. As restrições comerciais são implementadas de forma transversal a todo o pescado e frota de determinado país, independentemente de terem, ou não, activamente sido envolvidos em pesca INN. Daqui resultam impactos desproporcionais, em particular em relação a pequenos operadores que terão dificuldade em ultrapassar o embargo ao contrário de grandes operadores que têm meios para encontrar uma nova bandeira para a sua frota. ${ }^{31}$ Ou seja, as sanções europeias parecem algo cegas, injustas e, enfim, em boa parte ineficazes.

\section{RASTREABILIDADE}

A rastreabilidade (traceability) do pescado é também uma forma de, por um lado, combater as pescas INN e, por outro, proteger os consumidores europeus permitindo seguir o peixe que come desde a sua captura até ao prato, passando pelos vários intermediários, nomeadamente importador/primeiro comprador, processador/ transformador, transportador, grossista e retalhista, o que, no final, traduz a influência extraterritorial do Direito europeu.

Essa solução, hoje suportada em tecnologia que pode passar por códigos, rótulos e/ou aplicações de telemóvel, implica, porém, ao longo de toda a cadeia produtiva, custos com a sua implementação, que podem, ou não, ser repercutidos no preço a pagar pelo consumidor final. Com efeito, é necessário, por parte dos operadores, um investimento adicional (exemplo: equipamento e sistema de dados, pessoal qualificado, mais espaço de armazenagem para devida separação de lotes) e verificam-se mais custos de operação (recolha, armazenamento e disponibilização de informação, separação de lotes). ${ }^{32}$

Todavia, considera-se a medida proporcional e adequada perante os vários benefícios alcançados, mormente ganhos de transparência, concorrência leal e combate pesca INN, segurança alimentar e mais facilidade na limitação de danos, confiança do consumidor e melhor compreensão dos ciclos de produção e oferta. ${ }^{33}$

Nesta matéria da rastreabilidade das pescas, observa-se, contudo, alguma complexidade, pois, no Direito europeu, verifica-se a sobreposição com rastreabilidade alimentar, em especial com o enquadramento decorrente do Codex Alimentarius, da ISO 8402: 1994 e do Regulamento n 178/2002/CE, para além dos problemas e insuficiências acima identificados com um sistema de certificação de captura baseado

\footnotetext{
31 G. Hosch (20|6). viii.

32 I.C. Goulding (2016). Manual on Traceability Systems for Fish and Fishery Products, CRFM Special Publication, $n^{\circ}$ 13, 13.

33 I.C. Goulding (2016). 13-14. 
em papelada e sem registro central, sem ainda a efectiva aplicação do disposto no artigo $51^{\circ} n^{\circ} 2$ do Regulamento $n^{\circ}$ 1005/2008/CE sobre um sistema de assistência mútua, que inclui um sistema de informação automatizado, conhecido por "sistema de informação sobre a pesca INN", gerido pela Comissão ou por um organismo por ela designado, destinado a apoiar as autoridades competentes na prevenção, investigação e repressão da pesca INN.

Os requisitos de rastreabilidade da União Europeia, previstos no Regulamento n० |78/2002/CE, aplicam-se apenas dentro do espaço europeu, ou seja, não têm efeito extraterritorial. Desse modo, aplicam-se do importador ao revendedor (ou seja, o importador deve poder identificar seu fornecedor num terceiro país - um passo atrás). Porém, o próprio exportador, em país terceiro, não está vinculado à rastreabilidade. No entanto, pode ter ainda assim obrigações de rastreabilidade, seja por via de um regime especial (exemplo: produtos de origem animal) ou devido a arranjos contratuais ou acordo internacional.

Nesses termos, há de atender ao Regulamento no 1379/2013/NE, relativo à rotulagem e rastreabilidade de pescas, incluindo o rótulo ecológico e a indicação de zona de captura.

Aliás, já o artigo $12^{\circ} \mathrm{n}^{\circ} 4$ do Regulamento Pesca INN, juntamente com o Regulamento $n^{\circ} 1010 / 2009 / C E$, para certificado de captura, procuram assegurar a plena rastreabilidade de todo o produto de pesca comercializado com a União Europeia, ao determinar que

"O certificado de captura contém todas as informações indicadas no modelo constante do anexo Il e é validado por uma autoridade pública do Estado de pavilhão dotada dos poderes necessários para certificar a exactidão das informações. De acordo com os Estados de pavilhão, no âmbito da cooperação estabelecida no n. ${ }^{\circ} 4$ do artigo $20{ }^{\circ}$, o certificado de captura pode ser estabelecido, validado ou apresentado por via electrónica ou substituído por sistemas electrónicos de rastreabilidade que assegurem o mesmo nível de controlo pelas autoridades."

Por seu lado, o Regulamento $n^{\circ}$ 1224/2009/CE estabelece um sistema de controlo comunitário para garantir o cumprimento das regras da Política Comum de Pescas. Dessa forma, toda a cadeia de produção e comercialização deve ser coberta por um regime de controlo que deve incluir um sistema coerente de rastreabilidade complementar das disposições do Regulamento n |78/2002/CE e deve também proteger os interesses dos consumidores, fornecendo as informações relativas aos produtos marinhos.

Ademais, o artigo $58^{\circ}$, referente à rastreabilidade do Regulamento $n^{\circ}$ |224/2009/ CE, estipula que:

1. "Sem prejuízo do disposto no Regulamento (CE) n. o 178/2002, deve ser possível rastrear todos os lotes dos produtos da pesca e da aquicultura em todas as fases da produção, transformação e distribuição, desde a captura ou recolha até à venda a retalho. 
2. Os produtos da pesca e da aquicultura colocados no mercado, ou susceptíveis de o ser, na Comunidade devem estar adequadamente rotulados para assegurar a rastreabilidade de cada lote.

3. Os lotes dos produtos da pesca e da aquicultura só podem ser fundidos ou divididos depois da primeira venda se for possível detectar o seu percurso até à fase da captura ou recolha.

4. Os Estados-Membros garantem que os operadores disponham de sistemas e procedimentos para identificar o operador que Ihes tenha fornecido lotes de produtos da pesca e da aquicultura e a que esses produtos tenham sido fornecidos. Essa informação é disponibilizada às autoridades competentes, a seu pedido.

5. Os requisitos mínimos de rotulagem e informações para cada lote de produtos da pesca e da aquicultura devem incluir, no mínimo, os seguintes elementos:

a. Número de identificação de cada lote;

b. Número de identificação externa e nome do navio de pesca ou nome da unidade de produção aquícola;

c. Código alfa-3 da FAO de cada espécie;

d. Data das capturas ou data de produção;

e. Quantidades de cada espécie expressas em quilogramas de peso líquido ou, quando apropriado, número de indivíduos;

f. $\quad$ Nome e endereço dos fornecedores;

g. Informações ao consumidor previstas no artigo $45^{\circ}$ do Regulamento $n$. 1379/20 3 Do Parlamento Europeu e do Conselho;

h. Informações que indiquem se os produtos da pesca foram ou não previamente congelados.

6. (...)

7. As informações enumeradas no $n$. 0 , alíneas a) a f), não se aplicam aos produtos da pesca ou da aquicultura importados na Comunidade e acompanhados de certificados de captura."

As importações de países terceiros exigem certificados de captura e estão isentas dos requisitos de rastreabilidade do controlo das pescas. Todavia, as importações de países extra-comunitários ainda estão sujeitas à necessidade de fornecer informações ao consumidor e ao comércio retalhista, em conformidade com o Regulamento $\mathrm{n}^{\circ}$ 1379/20 I 3/NE, que estabelece uma organização comum dos mercados nos produtos da pesca e da aquicultura (CMO) e que vem regular as indicações de rotulagem para todos os produtos da pesca e da aquicultura comercializados na União Europeia, independentemente do método de comercialização, oferecidos ao consumidor final ou a um comerciante retalhista.

Por último, importa fazer também uma referência ao Regulamento de Informação sobre Alimentos ao Consumidor (FIC) n | |69/20 I I/NE, que estabelece como informação obrigatória a fornecer: Designação comercial e nomes científicos; Méto- 
do de produção; Área de captura/país e corpo da água/país de produção; Artes de pesca; Descongelação; "Consumir antes de/Utilizar até"; e Alergénicos. Naturalmente poderá ser incluída, a título voluntário, outra informação.

Em suma, no caso de peixe fresco não processado e pré-embalado, a rotulagem (que pode também ser feita por cartazes ou pôsteres) deverá incluir obrigatoriamente a designação comercial e nome científico do peixe, o método de produção, a área de captura e a categoria de equipamento de produção, no âmbito do Regulamento CMO que, conjuntamente com o Regulamento FIC exige a aposição da data de validade/consumo preferencial. Este último diploma, por sua vez, obriga a inclusão da informação sobre o peso líquido, o operador alimentar e as condições de acondicionamento. Já de acordo com o Regulamento CMO será voluntária a prestação de informação sobre o porto e data de entrada, o código de resposta rápida e o rótulo de certificação.

A rastreabilidade surge, embora enredada em alguma complexidade e burocracia devido à sobreposição legislativa, como uma forma privilegiada de controlo da pesca INN e da exportação de preocupações ambientais internacionais e europeias que assim corroem aos poucos o princípio da soberania territorial.

Contudo, é possível fazer algumas comparações entre os vários regimes de rastreabilidade aqui citados, distinguindo entre a componente de segurança alimentar e a componente puramente pesca INN. ${ }^{34}$

No primeiro caso, o que se pretende com a regulação é, de acordo com o princípio da segurança dos consumidores, acautelar um elevado grau de segurança alimentar e protecção consumidores, tendo em conta o âmbito dos Estados-Membros e dos Estados operadores. A identificação refere-se a todos os produtos alimentares, incluindo produtos da pesca, por lote. $\bigcirc$ estabelecimento autorizado a abastecer $\mathrm{O}$ mercado da União deve ser licenciado, e os dados de captura e gestão são disponibilizados a pedido da autoridade competente, devendo a informação cumprir as regras de rotulagem de produtos alimentares e pescado (e derivados).

$\mathrm{Na}$ segunda situação, norteia-se a regulação por um princípio não centrado no consumo, numa perspectiva antropocêntrica pura, mas de pescas sustentáveis, com uma dimensão intergeracional e ambiental, procurando-se assegurar, junto dos Estados-Membros e de terceiros que comercializam com a União Europeia, o cumprimento das regras da Política Comum de Pescas e, portanto, prevenir, impedir e eliminar a prática de pesca INN. Para o efeito, todos os navios de pesca devem estar licenciados, e os produtos de peixe identificados ao entrar no mercado da União Europeia. Os dados de captura e gestão envolvem um esquema de certificação de cap-

${ }^{34}$ Vincent André (20I8). EU Requirements for Food Safety and Traceability of Fish and Fishery Products, International Seminar on Sustainable Seafood Value Chain: Traceability 28-30 November 2018, Shanghai, China. 
tura para todo o pescado e derivados comercializados com a e na União Europeia, consagrando-se, em vez de um sistema de rotulagem, um modelo harmonizado de certificado de captura que deverá acompanhar o pescado na cadeia produtiva.

\section{NOTAS FINAIS}

A sobrepesca e a pesca INN, por maioria de razão, são um problema transnacional que afecta não apenas o ambiente, em especial numa perspectiva de manutenção do equilíbrio ecológico e da biodiversidade, como também o ser humano, seja por via da insustentabilidade da actividade, seja pelo impacto na segurança alimentar e no mercado.

A dimensão global dessa Tragédia dos Comuns explica e justifica, para lá do desenvolvimento de negociações e soluções internacionais e multilaterais, a procura de mecanismos unilaterais que desincentivem a sua prática e que estendam extraterritorialmente os efeitos do Direito europeu devido a condutas que provocam impactos no mercado e ambiente comunitários mas também com origem e/ou efeitos em Estados terceiros. A União Europeia busca, mormente na área das pescas INN, suspostamente em nome do Bem Comum (mas também da concorrência sã), com as ferramentas comerciais, de certificação e rastreabilidade, promover e alcançar tanto um "efeito de Bruxelas" ${ }^{35}$ de facto como de jure, isto é, respectivamente a alteração das práticas dos operadores ao longo de toda a cadeia produtiva indo ao encontro dos standards europeus e alterações legislativas formais equivalentes nos países terceiros.

As soluções com maior ou menor efeito extraterritorial, mas que, como se apura do acima descrito e analisado, não consubstanciam um exemplo de pura extraterritorialidade com limitações na sua aplicação e presença de elos ao espaço europeu, passam, como se acabou de referir, por uma combinação de ferramentas comerciais e de certificação e rastreabilidade de captura. A sua maior eficácia implica necessariamente um sistema de rastreabilidade verificável que abranja de forma imparcial todos os operadores da cadeia de oferta/abastecimento, seja em Estados de pavilhão, porto, mercado ou processamento. Mais, conviria que fosse edificado em torno de um registro central certificado (ou de dados) que requer a submissão e validação online de dados em todas as etapas da cadeia. De outro modo, para evitar injustiças e ineficiências socioeconómicas, às vezes perversas, conviria um tratamento diferenciado, mesmo no plano sancionatório comercial, dos operadores, capacidade de país (paviIhão, costeiro, porto, mercado) e tipos de espécies e produtos envolvidos em pesca INN, com a fixação de normas e procedimentos claros sobre o que constitui a cláusula INN e a identificação de países (na sua qualidade de capacidade) e operadores, com registros públicos transparentes e promoção do diálogo com potenciais infractores.

35 Por todos, Anu Bradford (20 I2). The Brussels Effect, Northwestern University Law Review, Vol. 107, $\mathrm{n}^{\circ}$ ।. 
Em última análise, dever-se-ia, nesta matéria, fomentar soluções regionais e internacionais (por exemplo via Organização Mundial do Comércio (OMC)), procurando a multilateralização dos instrumentos comerciais e dos sistemas de certificação e rastreabilidade, designadamente por meio de um reconhecimento mútuo e equivalência dos certificados. Ou seja, à semelhança do que sucede no plano das alterações climáticas, a União Europeia deverá prosseguir mais do que a imposição dos seus standards, a promoção de soluções internas equivalentes em países terceiros mas sobretudo o incentivo à construção de uma solução negociada global.

Por fim, sublinhe-se que o exercício de direitos procedimentais, como o acesso à Justiça ou a participação e audição (veja-se o caso Air Transport ou o processo de diálogo entre a União Europeia e Estados não cooperantes, ou as garantias previstas para os alegados operadores nas pescas INN) constitui uma limitação (justificada) do poder regulatório global unilateral ambiental da União Europeia, balizando-a e responsabilizando-a, pese embora em situações de impactos indirectos ou difusos em actores de Estados terceiros possam verificar-se algumas dificuldades de efectivação desses direitos. ${ }^{36}$ Ainda assim, trata-se de uma importante arma contra tentações hegemónicas.

\section{REFERÊNCIAS}

Alexandra Aragão. O Princípio do Nível Elevado de Protecção e a Renovação Ecológica do Direito do Ambiente, Almedina, Coimbra, 2006.

Anu Bradford. The Brussels Effect. Northwestern University Law Review, vol. 107, n. I, 2012.

B. Havel; J. Mulligan. The Triumph of Politics: Reflections on the Judgment of the Court of Justice of the European Union Validating the Inclusion of Non - EU Airlines in the Emissions Trading Scheme. Air and Space Law, Vol. 37, n. 3, 2012.

DEFRA. Analysis Paper on EU Emissions Trading Scheme Review Options. Londres, 2007.

Geert de Baere e Cedric Ryngaert. The ECJ's Judgment in Air Transport Association of America and the International Legal Context of the EU's Climate Change Policy, European Foreign Affairs Review, Vol. 18, n. ${ }^{\circ}$ 3, 2013.

Gilles Hosch. Trade Measures to Combat IUU Fishing: Comparative Analysis of Unilateral and Multilateral Approaches, International Centre for Trade and Sustainable Development, Issue Paper, Geneva, vii, 2016.

36 I. Hadjiyianni (2017). 542. 
I.C. Goulding. Manual on Traceability Systems for Fish and Fishery Products, CRFM Special Publication, $n^{\circ}$ |3, 2016.

IETA. Linking the EU ETS with Emerging Emissions Trading Schemes, Toronto e Genebra, 2006.

loanna Hadjiyianni. The Extraterritorial Reach of EU Environmental Law and Access to Justice by Third Country Actors, European Papers, Vol. 27, n. ${ }^{\circ}$ 2, 2017.

J. de Sépibus. Linking the EU Emissions Trading Scheme to JI, CDM and Post-2012 International Offsets. A Legal Analysis and Critique of the EU ETS and the Proposals for its Third Trading Period, NCCR Trade Regulation, Working Paper n. ${ }^{\circ}$ 2008/I 8, 2008.

J. Jaffe e R.N. Stavins. Linkage of Tradable Permit Systems in International Climate Policy Architecture, NBER, Working Paper n. 14432, Cambridge, MA, 2008.

J. Chevallier e N. Raffin. Linking Emissions Trading Schemes: An Assessment with Regard to Environmental Efficiency, 2008.

J.F. Green. The Regime Complex for Emissions Trading: The Role of Private Authority, Princeton University, Paper presented to the International Studies Association San Francisco, CA, 2008.

Joanne Scott. Extraterritoriality and Territorial Extension in EU Law, The American Journal of Comparative Law, American Journal of Comparative Law, n. 62, 2014.

M. Tatsutani e W.A. Pizer. Managing Costs in a U.S. Greenhouse Gas Trading Program. A Workshop Summary, RFF, Discussion Paper n. 08-23, I I- 12, 2008.

Natalie L. Dobson. The EU's conditioning of the 'extraterritorial' carbon footprint: A call for an integrated approach in trade law discourse, RECIEL, Vol. 27, n. I, 2018.

P. Criqui e A. Kitous. Impacts of Linking Jl and OMM Credits to European Emission Allowance Trading Scheme (KPI-ETS), Kyoto Control Implementation, 2003.

P. Criqui e L. Viguier. Régulation des Marchés de Droits D’Emission Négociables Pour le $\mathrm{CO}_{2}$ Une Proposition de Plafonds pour les Quantités et pour les Prix, Institut d'Economie et de Politique de l'Energie, Cahier de Recherche, n. I8, 2000.

R. Schüle e W. Sterk. Options and Implications of Linking the EU ETS with other Emissions Trading Schemes, European Parliament, DG Internal Policies of the Union, Policy Department Economic and Scientific Policy, 2008.

Rute Saraiva. A Herança de Quioto em Clima de Incerteza: Análise Jurídico-Económica do Mercado de Emissões num Quadro de Desenvolvimento Sustentado, Tese de Doutoramento, Faculdade de Direito da Universidade de Lisboa, Lisboa, 2009. 
T. James e P. Fusaro. Energy and Emissions Markets. Collision or Convergence? Wiley, Singapura, 2006.

Tomasz Koziel. Extraterritorial Application of EU Environmental Law - Implications of the ECJs Judgment in Air Transport Association of America, The Columbia Journal of European Law Online, n. ${ }^{\circ} 19,2012$.

Vincent André. EU Requirements for Food Safety and Traceability of Fish and Fishery Products, International Seminar on Sustainable Seafood Value Chain: Traceability 2830 November 2018, Shanghai, China, 2018.

Recebido em: 16/07/2019

Aprovado em: 29/08/2019 
